\title{
(RE)COLOCANDO O DIREITO JUNTO ÀS DINÂMICAS SOCIAIS: a institucionalização da sociologia jurídica nos currículos e o atravessamento da pesquisa sociojurídica na formação em direito
}

\section{Thais Lemos dos Santos}

\section{Palavras-Chave}

mapeamento; sociologia jurídica; sociologia do direito; ensino.

\section{SUMÁRIO}

1. Introdução; 2. Análise dos dados a respeito da institucionalização da disciplina sociologia jurídica nas faculdades de direito; 2.1. Nome da disciplina; 2.2. Ementas das disciplinas; 2.3. Bibliografia indicada; 2.4 . Formação dos professores; 3 . Características do campo constatadas a partir dos dados coletados; 4. Conclusão; 5. Referências.
Mestre em Ciências Jurídicas e Sociais pela Universidade Federa Fluminense - PPGSD, graduada em Direito pela Faculdade de Direito de Vitória - FDV. E-mail: thaislemosdossantos@gmail.com

\section{Resumo}

O presente trabalho pretende mapear a institucionalização da sociologia do direito nas faculdades de direito indicadas pelo selo OAB Recomenda. Para tanto, foram analisados os dados obtidos a partir de busca nos sites das instituições de ensino objeto do presente estudo, bem como das informações enviadas por e-mail pela secretaria, a respeito do formato e do ensino da sociologia do direito ou da sociologia jurídica (neste estudo utilizadas como sinônimos). Por isso, buscou-se alguns dados específicos sobre essa disciplina nos currículos das instituições pesquisadas, em especial se há na estrutura curricular uma disciplina voltada ao seu ensino; qual a nomenclatura atribuída a ela; se a sua ementa deixa claro qual é o seu objeto e, por fim; se a bibliografia adotada abrange textos e livros próprios de sociologia jurídica ou de sociologia do direito, ou se indicam apenas livros e textos de outros campos do saber. Tal mapeamento mostra-se relevante na medida em que a legislação que rege o ensino jurídico atualmente privilegia a interdisciplinaridade dos saberes, sendo este o lugar da sociologia jurídica nos cursos de direito. 


\section{(RE)PLACING THE LAW NEXT TO THE SOCIAL DYNAMICS: the institutionalization of sociology of law in the curricula and the crossing of the socio-legal research in the law graduation}

Thais Lemos dos Santos

Keywords

mapping; legal sociology; sociology of law; teaching.

1 Mestre em Ciências Jurídicas e Sociais pela Universidade Federal Fluminense - PPGSD, graduada em Direito pela Faculdade de Direito de Vitória - FDV. E-mail: thaislemosdossantos@gmail.com

\begin{abstract}
This work intends to map the institutionalization of the sociology of law in the faculties of law indicated by the seal "OAB Recomenda". In order to do so, it analyzed the data obtained from the search of the sites of the educational institutions object of the present study, as well as the information sent by e-mail by the secretariat, regarding the format and teaching of the sociology of law or juridical sociology (in this study used as synonyms). Therefore, we searched for some specific data about this discipline in the curricula of the institutions studied, especially if there is in the curricular structure a discipline focused on its teaching; the nomenclature attributed to it; if your menu makes clear what your object is, and finally; if the bibliography adopted covers texts and books of legal sociology or sociology of law, or only books and texts from other fields of knowledge are indicated. Such mapping is relevant insofar as the legislation that governs legal education currently favors the interdisciplinarity of knowledge, which is the place of legal sociology in law courses.
\end{abstract}




\section{INTRODUÇÃO}

O presente trabalho pretende mapear a implementação dos textos normativos que regulamentam o ensino jurídico na prática, em especial à inserção da Sociologia Jurídica nos currículos das faculdades de direito.

Para tanto, foram analisados os dados que apontam para a institucionalização de uma disciplina nos cursos jurídicos, sendo tais dados obtidos a partir de busca nos sites das instituições de ensino objeto do presente estudo, bem como das informações enviadas por e-mail pela secretaria dos cursos quando as informações que constavam em seus sites não eram suficientes para a presente análise. Porém, importante notar que não se obteve a resposta de todos os e-mails enviados, de modo que não foi possível obter informações precisas acerca de determinadas instituições.

Quanto ao recorte escolhido para delimitar as instituições pesquisadas neste trabalho, optou-se por pesquisar as faculdades de direito indicadas pelo selo OAB Recomenda, o qual consiste em um indutor de qualidade do ensino jurídico elaborado e coordenado pela Ordem dos Advogados do Brasil. Ou seja, a indicação da faculdade de direito por meio do selo OAB Recomenda leva em consideração os critérios estabelecidos pela Comissão de Ensino Jurídico desta instituição. A opção por analisar os cursos jurídicos indicados por este selo se justifica, em um primeiro momento, pelo elevado número de faculdades de direito no país, o que impossibilitaria a análise de todos os cursos atualmente existentes. Deste modo, diante dos diversos recortes possíveis, o presente trabalho adotou o selo OAB Recomenda como o critério para a análise das instituições de ensino, tendo em vista que este abrange cursos localizados em todo o país e institui- ções públicas e privadas, mostrando-se um critério objetivo que a ponta a representatividade dos cursos jurídicos nacionais.No que se refere às informações buscadas nos sites das instituições, estas dizem respeito ao formato e ao ensino da sociologia do direito ou da sociologia jurídica nas faculdades de direito. Por isso, buscou-se alguns dados específicos sobre essa matéria nos currículos das instituições pesquisadas, em especial se há na estrutura curricular uma disciplina voltada ao seu ensino; qual a nomenclatura atribuída a ela; se a sua ementa deixa claro qual é o seu objeto e, por fim; se a bibliografia adotada abrange textos e livros próprios de sociologia jurídica ou de sociologia do direito, ou se indicam apenas livros e textos de outros campos do saber. Diante de tais informações será possível chegar a algumas conclusões a respeito da institucionalização deste conteúdo nas faculdades de direito atualmente, considerando o previsto pela Resolução nº 09/2004 do CNE.

\section{ANÁLISE DOS DADOS A RESPEITO DA INSTITUCIONALIZAÇÃO DA DISCIPLINA SOCIOLOGIA JURÍDICA NAS FACULDADES DE DIREITO}

Inicialmente, importante notar que ao contrário do que previa a Portaria $n^{\circ} 1.886 / 94$, a atual Resolução nº 09/2004 não diferencia a sociologia geral e jurídica, o que se prevê é que o curso de graduação em direito contemple conteúdos essenciais de sociologia. Assim, considerando o atual texto normativo, em especial às normas referentes à sociologia, passa-se a analisar os dados obtidos nos sites das instituições pesquisadas, a fim de verificar como se deu a institucionalização da sociologia ou da sociologia jurídica nas faculdades de direito. 
Quanto aos dados, em uma primeira análise buscou-se verificar se há nos currículos das instituições pesquisadas uma disciplina direcionada ao ensino da sociologia, e em caso positivo qual é o nome dado a ela. Com este exercício, buscou-se identificar como as instituições estavam fazendo a leitura do artigo $5^{\circ}$ da Resolução. Além disso, se a atribuição de nomenclatura pelas instituições seguia alguma tendência que pode ser observada ou se esta tarefa foi realizada de maneira instintiva, sem se preocupar com alguma lógica preestabelecida.

Posteriormente, a análise se expande para o conteúdo, sendo que a partir da identificação do programa da disciplina e da bibliografia sugerida pelo professor, buscou-se verificar se disciplinas com nomenclaturas iguais seguem a mesma indicação de con- teúdo e de bibliografia, buscando, com isso, verificar se há alguma relação entre o nome e o conteúdo ministrado. Por fim, será analisado o perfil acadêmico do docente que ministra a disciplina.

\subsection{Nome da disciplina}

A primeira hipótese testada foi quanto à existência de uma disciplina específica voltada exclusivamente ao ensino da Sociologia Jurídica ou da Sociologia do Direito nos cursos jurídicos pesquisados. Esta análise se mostrou relevante para verificar a leitura que as faculdades de direito fazem acerca da exigência quanto à inclusão dos conteúdos essenciais de sociologia nos seus currículos.

A tabela e o gráfico abaixo demonstram quais foram os dados obtidos:

\begin{tabular}{|c|c|c|c|c|}
\hline REGIÃO & ESTADO & NOME & SIGLA & DISCIPLINA \\
\hline Norte & Acre & Universidade Federal do Acre & UFAC & Sociologia do Direito \\
\hline Norte & Amazonas & Universidade Federal do Amazonas & UFAM & Sociologia Geral e Jurídica \\
\hline Norte & Amazonas & Universidade do Estado do Amazonas & UEA & Sociologia Geral e Jurídica \\
\hline Norte & Pará & Universidade Federal do Pará & UFPA & Sociologia Jurídica \\
\hline Norte & Pará & $\begin{array}{l}\text { Universidade Federal do Sul e Sudeste } \\
\text { do Pará }\end{array}$ & UNIFESSPA & Sociologia Jurídica \\
\hline Norte & Pará & $\begin{array}{l}\text { Universidade Federal do Oeste do } \\
\text { Pará }\end{array}$ & UFOPA & Sociologia Jurídica \\
\hline Norte & Pará & Centro Universitário do Estado do Pará & CESUPA & Sociologia Geral e do Direito \\
\hline Norte & Rondônia & Universidade Federal do Rondônia & UNIR & Sociologia Aplicada ao Direito \\
\hline Norte & Tocantins & Universidade Federal do Tocantins & UFT & Sociologia Jurídica \\
\hline Nordeste & Alagoas & Universidade Federal de Alagoas & UFAL & Sociologia do Direito I e II \\
\hline Nordeste & Bahia & Universidade Federal da Bahia & UFBA & Sociologia Jurídica \\
\hline Nordeste & Bahia & Universidade do Estado da Bahia & UNEB & Sociologia Jurídica \\
\hline Nordeste & Bahia & Faculdade Nobre de Feira de Santana & FAN & Currículo não cadastrado \\
\hline Nordeste & Bahia & $\begin{array}{l}\text { Universidade Estadual de Feira de } \\
\text { Santana }\end{array}$ & UEFS & Currículo não cadastrado \\
\hline Nordeste & Bahia & Universidade Estadual de Santa Cruz & UESC & $\begin{array}{l}\text { Elementos de Sociologia e Antropologia } \\
\text { Jurídicas }\end{array}$ \\
\hline Nordeste & Bahia & Faculdade Baiana de Direito e Gestão & - & $\begin{array}{l}\text { Introdução à Sociologia e à Sociologia } \\
\text { Jurídica }\end{array}$ \\
\hline
\end{tabular}




\begin{tabular}{|c|c|c|c|c|}
\hline Nordeste & Bahia & Universidade de Salvador & UNIFACS & Sociologia Jurídica \\
\hline Nordeste & Bahia & $\begin{array}{l}\text { Universidade Estadual do Sudoeste } \\
\text { da Bahia }\end{array}$ & UESB & Sociologia Jurídica \\
\hline Nordeste & Ceará & Universidade Federal do Ceará & UFC & Sociologia Geral e Jurídica \\
\hline Nordeste & Ceará & $\begin{array}{l}\text { CRATO - Universidade Regional do } \\
\text { Cariri }\end{array}$ & URCA & Sociologia Geral e Jurídica \\
\hline Nordeste & Ceará & Centro Universitário Christus & - & $\begin{array}{l}\text { Metodologia da Pesquisa em Ciências } \\
\text { Sociais e Introdução às Ciências Sociais }\end{array}$ \\
\hline Nordeste & Ceará & Faculdade Farias Brito & FFB & $\begin{array}{l}\text { Conceitos de Sociologia e Antropologia } \\
\text { Jurídicas }\end{array}$ \\
\hline Nordeste & Ceará & Faculdade Sete de Setembro & FA7 & Sociologia do Direito \\
\hline Nordeste & Ceará & $\begin{array}{l}\text { Universidade Estadual do Vale do } \\
\text { Acaraú }\end{array}$ & UVA & Sociologia Geral e Jurídica \\
\hline Nordeste & Maranhão & Universidade Federal do Maranhão & UFMA & Sociologia Geral e Jurídica \\
\hline Nordeste & Maranhão & $\begin{array}{l}\text { Unidade de Ensino Superior Dom } \\
\text { Bosco }\end{array}$ & UNDB & Sociologia Jurídica \\
\hline Nordeste & Paraíba & Universidade Federal da Paraíba & UFPB & Sociologia Geral e Jurídica \\
\hline Nordeste & Paraíba & $\begin{array}{l}\text { Universidade Federal de Campina } \\
\text { Grande }\end{array}$ & UFCG & Sociologia Geral e Jurídica \\
\hline Nordeste & Paraíba & Universidade Estadual da Paraíba & UEPB & Sociologia Geral e Jurídica \\
\hline Nordeste & Pernambuco & Universidade Federal de Pernambuco & UFPE & Sociologia do Direito \\
\hline Nordeste & Pernambuco & Faculdade Damas da Instrução Cristã & FADIC & Sociologia Jurídica \\
\hline Nordeste & Pernambuco & Universidade Católica de Pernambuco & UNICAP & Antropologia e Sociologia Jurídica \\
\hline Nordeste & Piauí & Universidade Federal de Piauí & UFPI & Sociologia Jurídica \\
\hline Nordeste & Piauí & Universidade Estadual do Piauí & UESPI & Sociologia Jurídica \\
\hline Nordeste & Piauí & $\begin{array}{l}\text { Instituto de Ciências Jurídicas e } \\
\text { Sociais Professor Camillo Filho }\end{array}$ & - & Sociologia Geral e Jurídica \\
\hline Nordeste & $\begin{array}{l}\text { Rio Grande do } \\
\text { Norte }\end{array}$ & $\begin{array}{l}\text { Universidade Federal do Rio Grande } \\
\text { do Norte }\end{array}$ & UFRN & Sociologia Jurídica \\
\hline Nordeste & $\begin{array}{l}\text { Rio Grande do } \\
\text { Norte }\end{array}$ & $\begin{array}{l}\text { Universidade do Estado do Rio Grande } \\
\text { do Norte }\end{array}$ & UERN & Sociologia Jurídica \\
\hline Nordeste & Sergipe & Universidade Federal de Sergipe & UFS & Sociologia Geral e Jurídica \\
\hline Centro-Oeste & Distrito Federal & Universidade de Brasília & UnB & Sociologia do Direito \\
\hline Centro-Oeste & Distrito Federal & Centro Universitário de Brasília & UNICEUB & Sociologia Geral e Jurídica \\
\hline Centro-Oeste & Distrito Federal & $\begin{array}{l}\text { Centro Universitário do Distrito } \\
\text { Federal }\end{array}$ & UDF & Sociologia Geral e Jurídica \\
\hline Centro-Oeste & Distrito Federal & Faculdade Processus & PFD & Sociologia Geral e Jurídica \\
\hline Centro-Oeste & Goiás & Universidade Federal de Goiás & UFG & Sociologia Jurídica \\
\hline Centro-Oeste & Mato Grosso & Universidade Federal de Mato Grosso & UFMT & Sociologia Geral e do Direito \\
\hline Contro-Oeste & Mato Grosso & $\begin{array}{l}\text { Universidade do Estado de Mato } \\
\text { Grosso }\end{array}$ & UNEMAT & Sociologia do Direito \\
\hline Centro-Oeste & $\begin{array}{l}\text { Mato Grosso } \\
\text { do Sul }\end{array}$ & $\begin{array}{l}\text { Universidade Federal de Mato Grosso } \\
\text { do Sul }\end{array}$ & UFMS & Antropologia e Sociologia Jurídicas I e II \\
\hline Centro-Oeste & $\begin{array}{l}\text { Mato Grosso } \\
\text { do Sul }\end{array}$ & $\begin{array}{l}\text { Universidade Federal da Grande } \\
\text { Dourados }\end{array}$ & UFGD & Sociologia Jurídica e Antropologia \\
\hline
\end{tabular}




\begin{tabular}{|c|c|c|c|c|}
\hline Centro-Oeste & $\begin{array}{l}\text { Mato Grosso } \\
\text { do Sul }\end{array}$ & $\begin{array}{l}\text { Universidade Estadual de Mato Grosso } \\
\text { do Sul }\end{array}$ & UEMS & Sociologia Jurídica \\
\hline Sudeste & Espírito Santo & Universidade Federal do Espírito Santo & UFES & Sociologia Aplicada ao Direito \\
\hline Sudeste & Espírito Santo & Universidade Vila Velha & UVV & Sociologia do Direito \\
\hline Sudeste & Espírito Santo & Faculdades Integradas de Vitória & FDV & Sociologia do Direito \\
\hline Sudeste & Espírito Santo & $\begin{array}{l}\text { Faculdades Integradas Espírito } \\
\text { Santenses }\end{array}$ & FAESA & Sociologia e Antropologia \\
\hline Sudeste & Minas Gerais & Universidade Federal de Minas Gerais & UFMG & Sociologia Jurídica \\
\hline Sudeste & Minas Gerais & Universidade Federal de Ouro Preto & UFOP & Sociologia Jurídica \\
\hline Sudeste & Minas Gerais & Universidade Federal de Juiz de Fora & UFJF & Sociologia do Direito \\
\hline Sudeste & Minas Gerais & Universidade Federal de Uberlândia & UFU & Sociologia Jurídica \\
\hline Sudeste & Minas Gerais & Universidade Federal de Viçosa & UFV & Sociologia do Direito \\
\hline Sudeste & Minas Gerais & Centro Universitário Newton Paiva & - & Antropologia e Sociologia Jurídica \\
\hline Sudeste & Minas Gerais & Escola Superior Dom Helder Câmara & ESDHC & Sociologia Jurídica \\
\hline Sudeste & Minas Gerais & $\begin{array}{l}\text { Pontifícia Universidade Católica de } \\
\text { Minas Gerais }\end{array}$ & PUC-Minas & Sociologia Jurídica \\
\hline Sudeste & Minas Gerais & Universidade FUMEC & FUMEC & Ciências Sociais Aplicadas ao Direito \\
\hline Sudeste & Minas Gerais & $\begin{array}{l}\text { Universidade do Estado de Minas } \\
\text { Gerais }\end{array}$ & UEMG & Sociologia \\
\hline Sudeste & Minas Gerais & Faculdade Metodista Granbery & FMG & Sociologia \\
\hline Sudeste & Minas Gerais & Faculdades Integradas Vianna Junior & FIVJ & Sociologia Jurídica \\
\hline Sudeste & Minas Gerais & Centro Universitário de Lavras & UNILAVRAS & Sociologia Geral e Jurídica \\
\hline Sudeste & Minas Gerais & $\begin{array}{l}\text { Universidade Estadual de Montes } \\
\text { Claros }\end{array}$ & UNIMONTES & Sociologia Jurídica \\
\hline Sudeste & Minas Gerais & Faculdade de Direito Milton Campos & FDMC & Sociologia Jurídica \\
\hline Sudeste & Minas Gerais & Centro Universitário de Patos de Minas & UNIPAM & Sociologia Jurídica \\
\hline Sudeste & Minas Gerais & Faculdade Pedro Leopoldo & FPL & Sociologia Geral e Jurídica \\
\hline Sudeste & Minas Gerais & $\begin{array}{l}\text { Faculdade Dinâmica do Vale do } \\
\text { Piranga }\end{array}$ & FADIP & Sociologia e Antropologia \\
\hline Sudeste & Minas Gerais & $\begin{array}{l}\text { Escola Superior de Administração, } \\
\text { Marketing e Comunicação de } \\
\text { Uberlândia }\end{array}$ & $\begin{array}{l}\text { ESAMC de } \\
\text { Uberlândia }\end{array}$ & Sociologia Geral e Jurídica \\
\hline Sudeste & Minas Gerais & Universidade de Uberaba & UNIUBE & Sociologia e Antropologia Jurídica \\
\hline Sudeste & Rio de Janeiro & $\begin{array}{l}\text { Universidade Federal do Rio de } \\
\text { Janeiro }\end{array}$ & UFRJ & Sociologia e Antropologia Jurídica \\
\hline Sudeste & Rio de Janeiro & $\begin{array}{l}\text { Universidade Estadual do Rio de } \\
\text { Janeiro }\end{array}$ & UERJ & $\begin{array}{l}\text { Introdução à Sociologia Jurídica; } \\
\text { Sociologia Jurídica I; } \\
\text { Sociologia Jurídica II. }\end{array}$ \\
\hline Sudeste & Rio de Janeiro & $\begin{array}{l}\text { Universidade Federal do Estado do Rio } \\
\text { de Janeiro }\end{array}$ & UNIRIO & Sociologia Jurídica \\
\hline Sudeste & Rio de Janeiro & Universidade Federal Fluminense & UFF & Sociologia e Direito I e II \\
\hline Sudeste & Rio de Janeiro & Universidade Estácio de Sá & UNESA & Sociologia Jurídica e Judiciária \\
\hline Sudeste & Rio de Janeiro & Escola de Direito do Rio de Janeiro & FGV & Sociologia Jurídica \\
\hline
\end{tabular}




\begin{tabular}{|c|c|c|c|c|}
\hline Sudeste & Rio de Janeiro & $\begin{array}{l}\text { Faculdade de Ciências Sociais } \\
\text { Aplicadas }\end{array}$ & IBMEC & Direito, Pessoa e Sociedade \\
\hline Sudeste & Rio de Janeiro & $\begin{array}{l}\text { Pontifícia Universidade Católica do Rio } \\
\text { de Janeiro }\end{array}$ & PUC-Rio & $\begin{array}{l}\text { Sociologia do Direito e da Administração } \\
\text { da Justiça }\end{array}$ \\
\hline Sudeste & São Paulo & Universidade de São Paulo & $\begin{array}{l}\text { USP } \\
\text { USP/RP }\end{array}$ & $\begin{array}{l}\text { Sociologia Jurídica } \\
\text { Sociologia do Direito }\end{array}$ \\
\hline Sudeste & São Paulo & Faculdade de Ciências Econômicas & FACAMP & Sociologia Jurídica \\
\hline Sudeste & São Paulo & $\begin{array}{l}\text { Pontifícia Universidade Católica de } \\
\text { Campinas }\end{array}$ & PUC-Campinas & Sociologia do Direito \\
\hline Sudeste & São Paulo & Universidade Presbiteriana Mackenzie & Mackenzie & Sociologia do Direito \\
\hline Sudeste & São Paulo & Faculdade de Direito de Franca & FDF & $\begin{array}{l}\text { Fundamentos Socio-Antropológicos do } \\
\text { Direito }\end{array}$ \\
\hline Sudeste & São Paulo & $\begin{array}{l}\text { Universidade Estadual Paulista Julio } \\
\text { de Mesquita Filho }\end{array}$ & UNESP & Sociologia do Direito \\
\hline Sudeste & São Paulo & $\begin{array}{l}\text { Centro Universitário Antônio Eufrásio } \\
\text { de Toledo de Presidente Prudente }\end{array}$ & FIAETPP & Sociologia I e II \\
\hline Sudeste & São Paulo & Centro Universitário Uniseb & - & Não tem site. \\
\hline Sudeste & São Paulo & Universidade de Ribeirão Preto & UNAERP & Sociedade e Cultura \\
\hline Sudeste & São Paulo & $\begin{array}{l}\text { Escola Superior de Administração, } \\
\text { Marketing e Comunicação de Santos }\end{array}$ & ESAMC S & Sociologia Geral e Jurídica \\
\hline Sudeste & São Paulo & $\begin{array}{l}\text { Faculdade de Direito de São Bernardo } \\
\text { do Campo }\end{array}$ & FDSBC & Antropologia e Sociologia do Direito \\
\hline Sudeste & São Paulo & Escola de Direito de São Paulo & Direito GV & Sociologia Jurídica \\
\hline Sudeste & São Paulo & $\begin{array}{l}\text { Faculdade de Direito Professor } \\
\text { Damásio de Jesus }\end{array}$ & FDDJ & Currículo não cadastrado no site \\
\hline Sudeste & São Paulo & $\begin{array}{l}\text { Pontifícia Universidade Católica de } \\
\text { São Paulo }\end{array}$ & PUC & Sociologia Jurídica \\
\hline Sudeste & São Paulo & Universidade São Judas Tadeu & USJT & Sociologia Jurídica \\
\hline Sul & Paraná & Universidade Federal do Paraná & UFPR & Direito e Sociedade \\
\hline Sul & Paraná & Universidade Norte do Paraná & UNOPAR & Homem, Cultura e Sociedade \\
\hline Sul & Paraná & $\begin{array}{l}\text { Faculdade de Ciências Aplicadas de } \\
\text { Cascavel }\end{array}$ & UNIVEL & Antropologia e Sociologia do Direito \\
\hline Sul & Paraná & Centro Universitário de Curitiba & UNICURITIBA & Sociologia do Direito \\
\hline Sul & Paraná & $\begin{array}{l}\text { Centro Universitário Franciscano do } \\
\text { Paraná }\end{array}$ & FAE & Sociologia Jurídica \\
\hline Sul & Paraná & $\begin{array}{l}\text { Pontifícia Universidade Católica do } \\
\text { Paraná }\end{array}$ & PUC-PR & Sociologia Jurídica \\
\hline Sul & Paraná & Universidade Positivo & UP & Sociologia do Direito e Criminologia \\
\hline Sul & Paraná & Universidade Estadual de Londrina & UEL & Sociologia e Ciência Política \\
\hline Sul & Paraná & $\begin{array}{l}\text { Universidade Estadual do Oeste do } \\
\text { Paraná }\end{array}$ & UNIOESTE & Sociologia Geral e Jurídica \\
\hline Sul & Paraná & Universidade Estadual de Maringá & UEM & Sociologia \\
\hline Sul & Paraná & $\begin{array}{l}\text { Universidade Estadual de Ponta } \\
\text { Grossa }\end{array}$ & UEPG & Ciências Sociais e Direito \\
\hline
\end{tabular}




\begin{tabular}{|c|c|c|c|c|}
\hline Sul & Paraná & $\begin{array}{l}\text { Universidade Estadual do Norte do } \\
\text { Paraná }\end{array}$ & UENP & Sociologia Geral e Jurídica \\
\hline Sul & $\begin{array}{l}\text { Rio Grande do } \\
\text { Sul }\end{array}$ & $\begin{array}{l}\text { Universidade Federal do Rio Grande } \\
\text { do Sul }\end{array}$ & UFRGS & Sociologia do Direito \\
\hline Sul & $\begin{array}{l}\text { Rio Grande do } \\
\text { Sul }\end{array}$ & Universidade Federal do Rio Grande & FURG & Direito, Sociedade e Justiça Social \\
\hline Sul & $\begin{array}{l}\text { Rio Grande do } \\
\text { Sul }\end{array}$ & Universidade Federal de Pelotas & UFPEL & Sociologia Jurídica \\
\hline Sul & $\begin{array}{l}\text { Rio Grande do } \\
\text { Sul }\end{array}$ & Universidade Federal de Santa Maria & UFSM & Sociologia Aplicada ao Direito \\
\hline Sul & $\begin{array}{l}\text { Rio Grande do } \\
\text { Sul }\end{array}$ & Universidade da Região da Campanha & URCAMP & Currículo não cadastrado \\
\hline Sul & $\begin{array}{l}\text { Rio Grande do } \\
\text { Sul }\end{array}$ & Universidade de Passo Fundo & UPF & Sociologia e Antropologia do Direito \\
\hline Sul & $\begin{array}{l}\text { Rio Grande do } \\
\text { Sul }\end{array}$ & Escola Superior do Ministério Público & ESMP/FMP & Sociedade e Crime \\
\hline Sul & $\begin{array}{l}\text { Rio Grande do } \\
\text { Sul }\end{array}$ & Faculdade Dom Alberto & FDA & $\begin{array}{l}\text { Sociologia Aplicada ao Direito (disciplina } \\
\text { EAD) }\end{array}$ \\
\hline Sul & Santa Catarina & $\begin{array}{l}\text { Universidade Federal de Santa } \\
\text { Catarina }\end{array}$ & UFSC & Sociologia do Direito \\
\hline Sul & Santa Catarina & Universidade Regional de Blumenau & FURB & Sociologia Jurídica \\
\hline Sul & Santa Catarina & $\begin{array}{l}\text { Complexo de Ensino Superior do } \\
\text { Estado de Santa Catarina }\end{array}$ & CESUSC & Sociologia do Direito \\
\hline Sul & Santa Catarina & Universidade da Região de Joinville & UNIVILLE & Sociologia Geral e Jurídica \\
\hline Sul & Santa Catarina & Centro Universitário Barriga Verde & UNIBAVE & Sociologia Jurídica \\
\hline Sul & Santa Catarina & Universidade do Sul de Santa Catarina & UNISUL & Sociologia Jurídica \\
\hline Sul & Santa Catarina & $\begin{array}{l}\text { Universidade do Oeste de Santa } \\
\text { Catarina }\end{array}$ & UNOESC & Sociologia Jurídica \\
\hline
\end{tabular}

Tabela 01: nomenclatura da disciplina nas Faculdades de Direito das instituições contempladas com o selo OAB Recomenda. Fonte: elaboração própria.

De acordo com os dados expostos na tabela acima, a grande maioria das instituições (79,50\%) oferece uma cadeira exclusiva ao ensino da sociologia jurídica, ou seja, a leitura realizada pelas instituições quanto à obrigatoriedade do ensino de conteúdos essenciais de sociologia nos cursos de direito é no sentido de que deve ser separada uma cadeira específica ao ensino de tal conteúdo, o que não significa, a princípio, que ele também não poderá ser ensinado, de maneira interdisciplinar, nas demais disciplinas.

Em relação à escolha do nome da disciplina, é interessante observar se há uma lógica que opera a seleção destes nomes, na tabela seguinte é possível verificar a quantidade de instituições que adotam cada nomenclatura: 


\begin{tabular}{|c|c|}
\hline NOME DA DISCIPLINA & NÚMERO DE INSTITUIÇÕES \\
\hline Sociologia Jurídica & 39 \\
\hline Sociologia do Direito & 18 \\
\hline Sociologia Geral e Jurídica & 12 \\
\hline Sociologia Aplicada ao Direito & 04 \\
\hline Antropologia e Sociologia Jurídica & 03 \\
\hline Antropologia e Sociologia do Direito & 02 \\
\hline Sociologia Geral e do Direito & 02 \\
\hline Sociologia e Antropologia Jurídica & 02 \\
\hline Ciências Sociais Aplicada ao Direito & 01 \\
\hline Conceitos de Sociologia e Antropologia Jurídica & 01 \\
\hline Ciências Sociais e Direito & 01 \\
\hline Direito, Pessoa e Sociedade & 01 \\
\hline Direito e Sociedade & 01 \\
\hline Direito, Sociedade e Justiça Social & 01 \\
\hline Elementos de Sociologia e Antropologia Jurídica & 01 \\
\hline Fundamentos Socio-Antropológicos do Direito & 01 \\
\hline Introdução à Sociologia e à Sociologia Jurídica & 01 \\
\hline Sociologia do Direito e da Administração da Justiça & 01 \\
\hline Sociologia do Direito e Criminologia & 01 \\
\hline Sociologia e Antropologia do Direito & 01 \\
\hline Sociologia e Direito & 01 \\
\hline Sociologia Jurídica e Antropologia & 01 \\
\hline Sociologia Jurídica e Judiciária & 01 \\
\hline Sociologia & 04 \\
\hline Metodologia da Pesquisa em Ciências Sociais e Introdução às Ciências Sociais & 01 \\
\hline Sociologia e Antropologia & 01 \\
\hline Homem, Cultura e Sociedade & 01 \\
\hline Sociedade e Cultura & 01 \\
\hline Sociologia e Ciência Política & 01 \\
\hline Sociedade e Crime & 01 \\
\hline Currículo não cadastrado & 04 \\
\hline Instituição não tem site & 01 \\
\hline
\end{tabular}

Tabela 02: nome da disciplina por número de instituições. Fonte: elaboração própria

A nomenclatura mais usada é "sociologia jurídica" (33,33\%), seguida de "sociologia do direito" (15,38\%) e de "sociologia geral e jurídica" (10,25\%). Isso revela que as instituições, ao destinarem uma cadeira à sociologia jurídica na faculdade de direito preocuparam-se em fazer coro à norma, demonstrando, por meio da nomenclatura da disciplina, o ensino do conteúdo de sociologia em um curso jurídico, demonstrando o cumpri- mento daquilo que os órgãos estatais formalizaram por meio da legislação vigente, o que não significa, necessariamente, que tenham se atentado à finalidade desta mudança curricular. Além disso, a opção por estes nomes também revela uma ausência de criatividade e inovação ao implementar o currículo aos moldes da Resolução $n^{\circ}$ 09/2004, na medida em que simplesmente reproduzem a nomenclatura clássica, uti- 
lizada desde antes da legislação em vigor. Outro aspecto que pode revelar essa ausência de inovação refere-se à bibliografia adotada e ao conteúdo ministrado nas aulas, os quais basicamente retomam aos clássicos, não havendo indicação quanto às recentes produções científicas no campo, como será visto adiante.

Por meio da busca de currículos nos sites das instituições analisadas, verificou-se que dos 122 (cento e vinte e dois) sites visitados, em 04 (quatro) deles não foi localizada nenhuma informação acerca da estrutura curricular do curso. Além disso, 01 (uma) das instituições analisadas não tem site na internet. Sendo assim, os dados abaixo não levarão em consideração as informações sobre essas instituições.

Verificou-se que em 04 (quatro) instituições há uma disciplina denominada "sociologia", sem fazer menção à sociologia jurídica ou à sociologia do direito. No Centro Universitário Cristhus, no Ceará a disciplina é dividida com matérias relativas à metodologia de pesquisa, na FADIP - Faculdade Dinâmica do Vale do Piranga, em Minas Gerais, a disciplina é dedicada ao ensino da sociologia e da antropologia, já na UEL - Universidade Estadual de Londrina, no Paraná, a disciplina é dividida entre os conteúdos de sociologia e de ciência política. Nas faculdades de direito da UNOPAR - Universidade do Norte do Paraná, e na UNAERP - Universidade de Ribeirão Preto, a disciplina é denominada "Homem, Cultura e Sociedade" e "Sociedade e Cultura", respectivamente, não havendo qualquer referência à ligação do estudo das ciências sociais com o direito. Na faculdade de direito da USMP/FMP - Escola Superior do Ministério Público, a disciplina é denomina "Sociedade e Crime", deixando clara a tendência em fazer uma conexão entre o estudo da sociologia com a criminologia.

Nas demais faculdades de direito há uma cadeira específica destinada ao estudo da sociologia jurídica, da sociologia do direito, da sociologia aplicada ao direito, da sociologia geral e jurídica, dentre outras nomenclaturas adotadas nas quais é possível identificar que esta tem como objeto a relação entre a sociologia e o direito.

Sendo assim, uma vez verificado que a grande maioria dos cursos optou por incluir uma disciplina voltada ao ensino do conteúdo de sociologia jurídica em seus currículos, também nos permite concluir que embora a Resolução n 09/2004 tenha privilegiado a institucionalização da matéria, ou seja, do conteúdo de sociologia, houve uma preocupação em institucionalizar a disciplina.

Fazendo uma análise quanto às regiões em que estão localizados os cursos jurídicos ora pesquisados, verifica-se que na região norte foram analisados 09 (nove) cursos, na região nordeste 28 (vinte e oito), na região centro-oeste 10 (dez), na região sudeste 48 (quarenta e oito) e, por fim, na região sul 27 (vinte e sete).

Em relação à região norte, verificou-se que a maior parte das faculdades optou por adotar as nomenclaturas clássicas de "sociologia jurídica" (33,33\%), seguida de "sociologia do direito" (22,22\%) e de "sociologia geral e jurídica" (22,22\%). Os nomes "sociologia aplicada ao direito" e "sociologia geral e do direito" foram escolhidos por 01 (uma) instituição cada.

Na região nordeste, observa-se que a maior parte das faculdades adotou a nomenclatura "sociologia jurídica" (35,71\%), a segunda nomenclatura mais utilizada é a "sociologia geral e jurídica" (32,14\%) e a denominação 
"sociologia do direito" foi adotada por 02 (duas) instituições diferentes, representando $7,14 \%$ do total. As demais foram adotadas por apenas 01 (uma) instituição, representando cada uma delas 3,5\%.

Já na região centro-oeste a nomenclatura mais utilizada foi a "sociologia geral e jurídica" (30\%), seguida de "sociologia jurídica" (20\%) e de "sociologia do direito" (20\%). As nomenclaturas "sociologia jurídica e antropologia", "sociologia geral e do direito" e "antropologia e sociologia jurídica", cada uma delas foi utilizada por 01 (uma) instituição.

A região sudeste é a que mais apresentou cursos de direito indicados pelo selo OAB Recomenda e, por isso, a região que mais teve cursos analisados na presente pesquisa. Nesta região a nomenclatura mais utilizada também foi "sociologia jurídica" (35,41\%), seguida por "sociologia do direito" (14,81\%) e "sociologia geral e jurídica" (11,11\%). Vale dizer que dos 48 (quarenta e oito) cursos analisados na região sudeste, 05 (cinco) deles $(10,41 \%)$ apresentam a disciplina "sociologia geral" ou "sociologia e antropologia".

A região sul segue a mesma tendência da região sudeste, na medida em que na maior parte de seus cursos a disciplina é denomina "sociologia jurídica" (25,92\%), seguida por "sociologia do direito" (14,81\%) e "sociologia geral e jurídica" (11,11\%). "Sociologia aplicada ao direito" foi a nomenclatura utilizada por O2 (duas) instituições (7,40\%) e uma delas possui na matriz curricular uma disciplina denominada "sociedade e crime".

Os dados a respeitos das regiões em que os cursos se encontram e as nomenclaturas atribuídas à disciplina não revelam muitas informações relevantes, na medida em que não se verifica uma lógica seguida pelas instituições considerando as peculiaridades re- gionais de cada curso, na verdade, opta-se pelo uso dos mesmos nomes em todas as regiões do país, havendo poucas alterações entre elas, revelando-se uma aleatoriedade nesta escolha.

A partir desses dados, passa-se a verificar a existência de uma relação entre o nome da disciplina e o conteúdo ministrado aos discentes do curso de direito. Esta análise será realizada por meio das ementas de cada disciplina.

\subsection{Ementas das disciplinas}

A análise da ementa das disciplinas acima listadas permitirá saber a percepção do corpo docente a seu respeito, isso porque as ementas, junto com as bibliografias, indicam a leitura que o professor faz sobre determinado conteúdo e com isso é possível verificar as inclinações teóricas e os objetivos da disciplina.

Em tese, na ementa das disciplinas consta um resumo conceitual e procedimental do seu conteúdo. Porém, desta análise não se observou um padrão seguido por todas as instituições, de modo que algumas ementas constam informações mais precisas, como o conteúdo ministrado ao longo do curso, o objetivo da disciplina, a metodologia aplicada, a forma de avaliação, ao passo que em outras ementas não há grandes esclarecimentos, havendo apenas informações esparsas.

Neste estudo, foram analisadas as ementas de 67 (sessenta e sete) disciplinas, já que, embora a pesquisa não tenha se restringido à busca da ementa no site da instituição, mesmo com o envio de e-mails solicitando que fossem disponibilizadas as informações necessárias, algumas instituições não res- 
ponderam ou não enviaram tais informações.

A análise das ementas foi realizada a partir do entendimento a respeito do que se considera como sendo conteúdos de sociologia do direito e de sociologia jurídica. Essa diferenciação foi realizada por alguns autores que se debruçaram sobre o tema, de modo que surgiram algumas classificações distintas com o intuito de agrupar determinados conteúdos ou de que se criasse um sistema de divisão levando em consideração o enfoque dado ao objeto estudado.

De acordo com a pesquisa realizada por Eliane Junqueira (2002), Renato Treves considera a sociologia jurídica uma sociologia produzida por juristas e a sociologia do direito uma sociologia feita por sociólogos (1978), já Jean Carbonnier atribui à sociologia jurídica um sentido mais amplo do que à sociologia do direito, pois esta última

(...) limitar-se-ia ao que constitui o próprio direito, às normas e instituições, enquanto que a sociologia jurídica compreenderia todos os fenômenos dos quais o direito pode ser causa, efeito ou ocasião, compreendidos os de violação, de inefectividade e de desvio (Carbonier como citado em Junqueira, 2002, p. 19).

José Eduardo Faria e Celso Campilongo utilizaram o sentido atribuído por Roberto Lyra Filho à sociologia jurídica, segundo o qual:

(...) falamos em Sociologia do Direito, enquanto se estuda a base social de um direito específico. Por exemplo, é Sociologia do Direito a análise da maneira por que o nosso direito estatal reflete a sociedade brasileira em suas linhas gerais (de poucas contradições e de mínima flexibilidade, dado o sistema, ainda visceral- mente autoritário, de pequenas 'aberturas', controladas, como um queijo suíço, perpetuamente a enrijecer-se, no receio de que os ratinhos da oposição alarguem os buracos). Toda aquela velha estrutura então se desvenda como elemento condicionante, que pesa sobre o país, obstaculizando as remodelações de forças internacionais, interessadas em que ao imperialismo não escape tão gordo quinhão. Sociologia jurídica, por outro lado, seria o exame do Direito em geral, como elemento do processo sociológico, em qualquer estrutura dada (...) (Lyra Filho, 1982, p. 72-73).

Neste contexto, o estudo do direito pode ser visto ora como instrumento de dominação, ora como instrumento de controle ou de mudança social, o pluralismo jurídico, o qual forma um conjunto competitivo de normas, contrastando o direito das classes oprimidas com o direito que a classe dominante deseja manter, como sendo matérias de interesse da sociologia jurídica. Por fim, o autor ressalta que embora haja diferenciações entre o sentido científico atribuído à sociologia do direito e à sociologia jurídica, estas realizam uma troca permanente de informações.

Porém, a diferenciação do campo científico abrangido pela sociologia do direito e pela sociologia jurídica não é unânime, por exemplo, André-Jean Arnaud trata os dois termos como sinônimos (1995a).

Para Eliane Junqueira (2002) a diferenciação entre a sociologia do direito e a sociologia jurídica existe e importa para delimitar o objeto da disciplina e o campo científico por ela explorado. Segundo a autora, adotando a classificação feita por Renato Treves, a sociologia do direito é o campo teórico que trabalha o direito redefinido pelas ciências 
sociais, por meio dos pressupostos teóricos e metodológicos desta. Já a sociologia jurídica seria uma disciplina cujo objetivo é introduzir uma visão sociológica na análise do direito, despertando o aluno para uma consciência crítica em relação à ordem jurídica.

A autora afirma, ainda, que nos cursos de direito deveria ser lecionada a sociologia produzida por sociólogos, atendendo às necessidades de formação fundamental, sociopolítica, técnica-jurídica do bacharel, de acordo com suas peculiaridades e com observância da interdisciplinaridade que tende a não acontecer com as disciplinas dogmáticas, a fim de garantir uma formação geral e sólida, humanística e axiológica adequada à argumentação, à interpretação e à valorização dos fenômenos jurídicos e sociais. Contudo, como ela mesmo aponta, é necessário questionar se o termo sociologia do direito não seria uma expressão muito genérica para designar esta pretensão.

Aliás, antes de definir o objeto da sociologia do direito, a autora entende necessário definir o próprio direito e questionar a possibilidade de uma sociologia do direito que não se limite ao direito estatal, mas que esteja voltada para o pluralismo jurídico e que, até mesmo, prescinda do direito enquanto seu objeto explícito. Por isso, afirma que ao que Ihe parece a denominação 'direito e sociedade' seja a mais adequada, pois permite que os limites da fronteira disciplinar sejam ultrapassados, passando a ter como referência o objeto de estudo da própria disciplina:

(...) ou seja, todas as relações entre direito e sociedade, vistas por múltiplas óticas (inclusive por óticas não sociológicas, já que o campo inclui a psicanálise, a literatura, a economia, a psicologia, a ciência política, a história, como ocorre na Law and Society Association, que constitui um espaço verdadeiramente interdisciplinar) (Junqueira, 2002, p. 20).

Considerando as classificações acima abordadas, a análise das ementas será realizada a partir da distinção entre sociologia jurídica e sociologia do direito sob o enfoque dado por Eliane Junqueira e Renato Treves. Assim, na presente análise foram extraídas das ementas informações a respeito do objeto da disciplina, se este consiste no estudo de como o direito opera socialmente, estudo típico da sociologia do direito, ou se consiste na explicação sociológica do direito, objeto de estudo da sociologia jurídica.

Outro recorte utilizado consiste na verificação dos programas estabelecidos por cada ementa, se eles se aproximam de um programa de sociologia ou de um programa de filosofia e de teoria geral do direito. Vale dizer que estes recortes também foram utilizados por Eliane Junqueira em sua pesquisa sobre o ensino da sociologia jurídica nas faculdades de direito (2002, p. 54).

Em relação ao programa apresentado na ementa da disciplina "direito, sociedade e justiça social" (FURG), verifica-se que seu objeto consiste na explicação sociológica do direito e se aproxima mais de um programa de sociologia. O mesmo se verifica na ementa da disciplina "direito e sociedade" (UFPR) e "sociologia geral e do direito" (UFMT), sendo que nestas últimas também estão inseridos temas atuais desenvolvidos em pesquisa empírica no campo sociojurídico, como sociologia das profissões, criminologia, direito e movimentos sociais.

Nas disciplinas "sociologia jurídica e antropologia" (UFGD), "antropologia e sociologia jurídica I e II" (UFMS) o objeto é identificar como o direito opera socialmente e os seus 
programas se aproximam mais de um programa de sociologia. No que se refere à disciplina "sociologia e antropologia jurídica" (UFRJ) o mesmo se observa em relação ao seu objeto e programa, porém, nesta estão inseridos outros temas, como direitos humanos, pluralismo cultural e práticas sociais.

Nas instituições pesquisadas em que a disciplina foi denominada "sociologia aplicada ao direito" (UNIR, UFES e UFSM) não foi possível verificar um padrão preestabelecido entre as suas ementas por compartilharem a mesma nomenclatura. Isso porque, embora todos os programas se aproximem de um programa de sociologia e todos eles tenham como objeto a explicação sociológica do direito, duas delas também trazem muitas influências de conteúdos que tratam de como o direito opera socialmente.

Em relação à disciplina "sociologia geral e jurídica", a análise das ementas se limitou às faculdades de direito da UFAM, da UFC, da UFMA, da UFCG, da UEPB, do Instituto de Ciências Sociais e Jurídicas Professor Camillo Filho, da UFS, da UNICEUB, da USAMC-Uberlândia e da UNIVILLE. Das 10 (dez) ementas analisadas, todos os programas se aproximam da sociologia, 05 (cinco) tem como objeto definir como o direito opera socialmente e 05 (cinco) tem como objeto a explicação sociológica do direito, sendo que em uma ementa também há um espaço destinado à pesquisa empírica em ciência social do direito e técnicas de pesquisa em sociologia do direito.

A disciplina "sociologia do direito" integra a estrutura curricular das faculdades de direito de 18 (dezoito) instituições pesquisadas, porém somente tivemos acesso à ementa dos cursos da UFAC, da UFAL, da UFPE, da UNEMAT, da UFJF, da UFV, da USP/RP, da
PUC-Campinas, da Mackenzie, da UFRGS, da UFSC e da CESUSC.

Verificou-se que 07 (sete) dos 12 (doze) programas tem como objeto a explicação sociológica do direito e 05 (cinco) deles é tem por objeto entender como o direito opera socialmente. Observou-se, também, que três desses programas trazem temas atuais de pesquisa empírica em direito, tanto de maneira genérica pela expressão "linhas e representantes atuais da sociologia jurídica no Brasil", quanto de maneira mais específica, como por exemplo "direito e movimentos sociais: indígenas, negros, mulheres, movimento sem terra, LGBTTs. Criminalização. Judicialização do social". Por fim, dois programas preveem o estudo de técnicas de pesquisa em sociologia do direito e da importância dessas técnicas.

A ementa da disciplina "sociologia jurídica" foi disponibilizada para as seguintes instituições: UFPA, UFOPA, UFT, UFBA, UNEB, UESB, UFPI, UFRN, UFG, UFMG, UFOP, UFU, UERJ, UNIRIO, USP/SP, UFPEL, PUC-Minas, UERN, UNIBAVE, UNOESC A DIREITO-GV. Vale mencionar que na UERJ a disciplina é dividida em "introdução à sociologia jurídica", "sociologia jurídica I" e "sociologia jurídica II", sendo assim todas as ementas foram analisadas, uma vez que todas as disciplinas são obrigatórias.

Em relação a este grupo foi observado que o objeto de 12 (doze) das 21 (vinte e uma) ementas analisadas trata de como o direito opera socialmente e em 09 (nove) delas o objeto é a explicação sociológica do direito.

No que tange à pesquisa, em 04 (quatro) ementas há temas atuais de pesquisa, tais como pesquisa em desigualdade de gênero, geração, raça, etnia e classe; direito alternativo; acesso à justiça; direitos humanos: inova- 
ção, transformações e novos direitos. Todas as ementas analisadas neste grupo trazem programas de sociologia, há, contudo, previsão de conteúdos filosóficos em uma delas.

Diante dos dados acima apresentados, não foi possível verificar a repetição do padrão escolhido, qual seja, disciplinas cujo objeto é a explicação científica a respeito de como o direito opera socialmente seriam denominadas "sociologia do direito" e disciplinas cujo objeto é a explicação sociológica do direito seriam denominadas "sociologia jurídica". Isso porque, não houve uma prevalência na escolha do objeto da disciplina levando-se em consideração o nome a ela atribuído. Assim, não se verificou nenhuma tendência ou tipo-ideal a partir dos quais os programas possam ser identificados. Inclusive, há programas que trazem temas que se identificam com os dois objetos. Porém, vale dizer que isso não parece uma questão problemática, na verdade, a ausência de orientação por parte da Resolução $n^{\circ}$ 09/2004 quanto ao conteúdo e à bibliografia a ser adotada pela disciplina pode ser um fator que desencadeia esta situação, sendo esta mais uma característica do que um defeito a ser corrigido.

De um modo geral, de todas as 67 (sessenta e sete) ementas analisadas verificou-se que 38 programas $(56,71 \%)$ são voltados à explicação sociológica do direito, enquanto 27 tem como objeto a explicação de como o direito opera socialmente (40,29\%). Apenas 08 programas tratam da pesquisa (11,94\%). Os temas atuais em sociologia e direito são tratados por 10 programas (14,94\%) e 91,04\% dos programas trazem conteúdos relativos à sociologia e à sociologia do direito, sendo que apenas 8,95\% deles misturam estes conteúdos com matérias relativas à filosofia e teoria do direito.
De toda essa análise, uma conclusão possível é a de que, diferente do resultado obtido por Eliane Junqueira em 2002, atualmente as ementas das disciplinas voltadas ao estudo da sociologia do direito ou da sociologia jurídica, não mais se aproximam de conteúdos de filosofia e de teoria do direito. Uma hipótese que pode justificar essa conclusão é a de que embora ainda não seja possível traçar um perfil acadêmico desta disciplina, verifica-se que ao longo dos anos ela está, pelo menos, conseguindo excluir aqueles conteúdos que não se harmonizam com o seu escopo. Desta forma, delimitando-se o alcance e as limitações do seu próprio campo, mostra-se cada vez menos necessária a utilização de conteúdos próprios de outros campos.

Há também outra conclusão possível que se refere à presença ainda tímida da temática de pesquisa nas ementas, apenas 11,94\% possuem previsão expressa quanto à pesquisa. Sendo assim, é relevante notar que a despeito da obrigatoriedade da matéria, bem como da previsão legal quanto ao incentivo à pesquisa científica no ensino superior como um todo, ao menos no que se refere à sociologia jurídica ou à sociologia do direito, esta ainda não é uma realidade. Por outro lado, nota-se que um número maior de ementas prevê temas atuais de pesquisas empíricas no campo sociojurídico, ou seja, de acordo com onze ementas alguns temas que integram a atual agenda de pesquisa em sociologia jurídica serão abordados ao longo do semestre, mais adiante iremos retomar aos temas estudados.

Por ora, vale concluir que a ausência de diálogo entre as pesquisas empíricas produzidas em sociologia jurídica e em sociologia do direito e o conteúdo ministrado nessas disciplinas aponta um sinal de que o que 
está sendo produzido pelos pesquisadores do campo não está sendo objeto de estudo dos alunos de direito, uma hipótese que pode justificar tal conclusão é a de que o direito ainda apresenta resistência quanto ao diálogo com outros campos.

\subsection{Bibliografia Indicada}

A análise da bibliografia das disciplinas também restou comprometida, tendo em vista que das 122 (cento e vinte e duas) instituições pesquisadas, apenas 52 (cinquenta e duas) disponibilizaram ou enviaram suas bibliografias.

Desta forma, de todas as 52 (cinquenta e duas) bibliografias analisadas, em 45 (quarenta e cinco), que representa $86,53 \%$ do total, constam livros de sociologia jurídica, sendo que a maior parte destes é no formato de Manual, indicando que o corpo docente da sociologia jurídica se rende ao clássico método dos manuais, muito utilizado na graduação em direito. Além disso, importante dizer que em 07 (sete) cursos não há previsão bibliográfica específica para o conteúdo de sociologia jurídica ou de sociologia do direito. Em 41 (quarenta e um) constam livros de sociologia geral, que variam desde a teoria sociológica clássica, até os autores contemporâneos.

Embora apenas uma ementa preveja conteúdos de filosofia, em 10 (dez) bibliografias analisadas constam livros e textos voltados à filosofia geral ou à filosofia do direito (19,23\%). Ademais, em 05 (cinco) delas também constam obras de criminologia. Em apenas 01 (uma) bibliografia aparece textos de ciência política. Em relação à antropologia, em 05 (cinco) bibliografias constam textos e livros deste campo, porém este número se justifica na medida em que em algumas faculdades a sociologia e a antropologia dividem a cadeira.

Diante dessa análise, percebe-se que a grande maioria dos cursos opta pelo ensino da sociologia jurídica ou da sociologia do direito por meio de manuais, sendo que em 07 (sete) cursos não há qualquer menção a livros ou textos próprios da sociologia jurídica ou do direito, deixando a disciplina a cargo de livros e textos de sociologia geral. Ou seja, em 13,46\% das bibliografias analisadas ainda não há um reconhecimento do conteúdo de sociologia jurídica ou de sociologia do direito.

Além disso, não se verifica linearidade e harmonia entre o objetivo da disciplina e o conteúdo efetivamente indicado aos alunos, o que pode ser atribuído à própria amplitude do campo e à dificuldade em estabelecer seus marcos acadêmicos de maneira delimitada, ao menos a nível de graduação.

Quanto à forte presença de conteúdos de sociologia geral, filosofia, criminologia e antropologia nas bibliografias analisadas, este intercâmbio e troca entre um campo e outro, ou outros, não parece ser um problema, na verdade, mostra-se benéfico ao estudante da graduação e também consiste no próprio objetivo traçado pela Resolução $n^{\circ}$ 09/2004. Porém, a desejada troca não pode se confundir com a substituição de um conteúdo por outro. Isto é, não havendo atenção quanto à abordagem dada aos objetos de estudo, é possível que a análise sociológica esteja sendo preterida, em relação à análise antropológica ou filosófica do objeto.

Segundo Eliane Junqueira, à época de sua pesquisa (2002), o ensino da sociologia jurídica era baseado no "cuspe e giz", ou seja, em aulas expositivo-dialogadas sem qual- 
quer utilização de metodologias inovadoras, pesquisas empíricas e raramente incitava o debate profundo dos temas ou tinha qualquer relação interdisciplinar. Se a proposta da Resolução n 09/2004, ao introduzir a matéria sociologia no eixo de formação fundamental do curso de direito, era torná-lo interdisciplinar, crítico, problematizante, histórico e não dogmático, percebe-se que, em geral, ainda não houve uma mudança signi- ficativa em relação à inserção da pesquisa e de novas metodologias no curso de direito, na medida em que somente constam livros ou textos sobre pesquisa ou metodologia de pesquisa em cinco bibliografias analisadas.

Por fim, os gráficos abaixo representam os temas tratados pela bibliografia, considerando tanto os outros campos do saber, como os temas próprios da sociologia e da sociologia do direito.

\section{Gráfico 01: conteúdo da bibliografia das disciplinas analisadas}

Bibliografia (Sociologia Geral e Jurídica x Outros Campos do Saber)

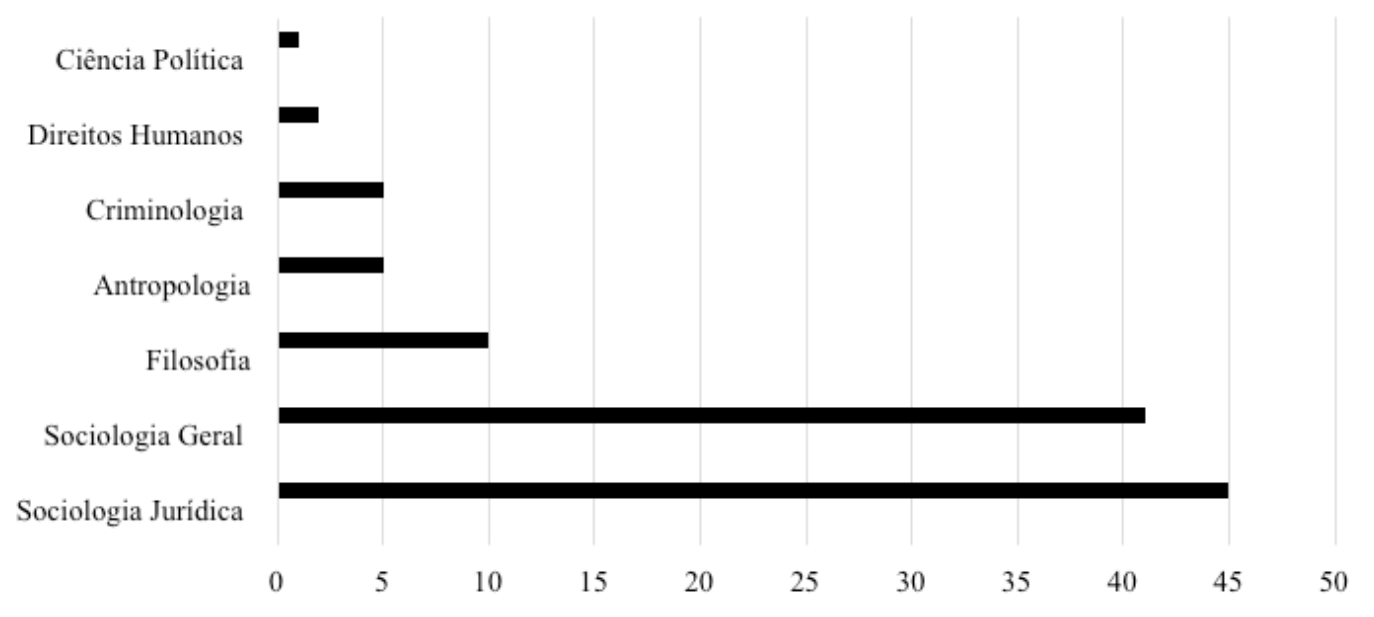

Fonte: elaboração própria.

\section{Gráfico 02: temas abordados nos materiais indicados nas bibliografias}

Bibliografia (Temas relacionados à Sociologia Jurídica)
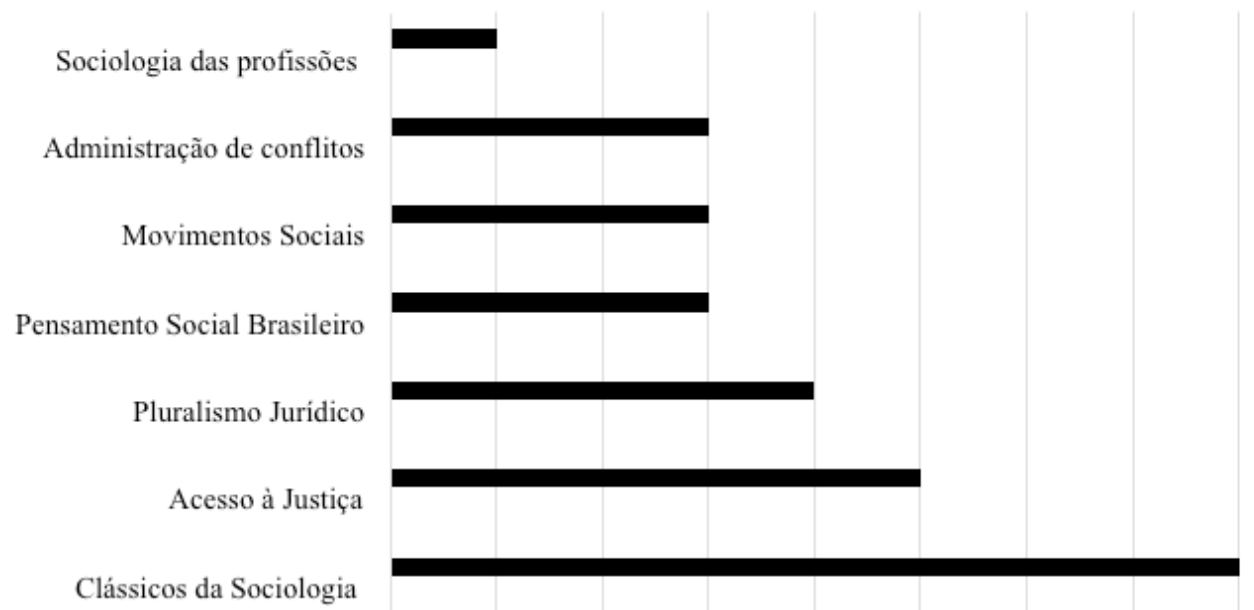
Em relação aos dados acima uma conclusão possível é a de que, embora exista uma agenda de pesquisa em sociologia do direito, sociologia jurídica, sociologia das profissões, administração institucional de conflitos e outras, apenas uma pequena parcela dos programas de sociologia jurídica da graduação em direito explora o conteúdo destes trabalhos. Para entender essa situação, parte-se da hipótese de que os próprios professores da disciplina, os quais em sua maioria são formados em direito, ainda não estão completamente contextualizados com tais pesquisas.

\subsection{Formação dos Professores}

Foi feita a análise da formação acadêmica dos professores de sociologia jurídica nas faculdades de direito, para tanto foi analisada a área de formação do docente, bem como a área em que realizou suas pós-graduações. No entanto mais uma vez, os resultados da pesquisa ficaram comprometidos tendo em vista que dos 122 (cento e vinte e dois) cursos analisados apenas tivemos acesso ao nome de 54 (cinquenta e quatro) professores, que lecionam em 40 (quarenta) faculdades de direito, isso porque em algumas faculdades a disciplina é dividida em mais de um semestre, sendo assim, a quantidade de professores é maior.

Em relação aos cursos e às áreas do conhecimento em que estes professores fizeram suas graduações e pós-graduações, respectivamente, verifica-se que 34 (trinta e quatro), ou seja, $62,96 \%$ dos professores possui graduação em direito e 13 (treze) em ciências sociais, isto é, $24,07 \%$. Portanto, verifica-se que o campo ainda é predominantemente formado por profissionais ligados à área jurídica, o que pode ser devido ao fato de a disciplina ser destinada a estudantes de graduação em direito. Há $\mathrm{O} 2$ (dois) professores com formação em teologia, 02 (dois) com formação em filosofia, há, também, professores com formação em comunicação social, engenharia, história, pedagogia e serviço social.

\section{Gráfico 03: formação acadêmica do corpo docente em nível de graduação}

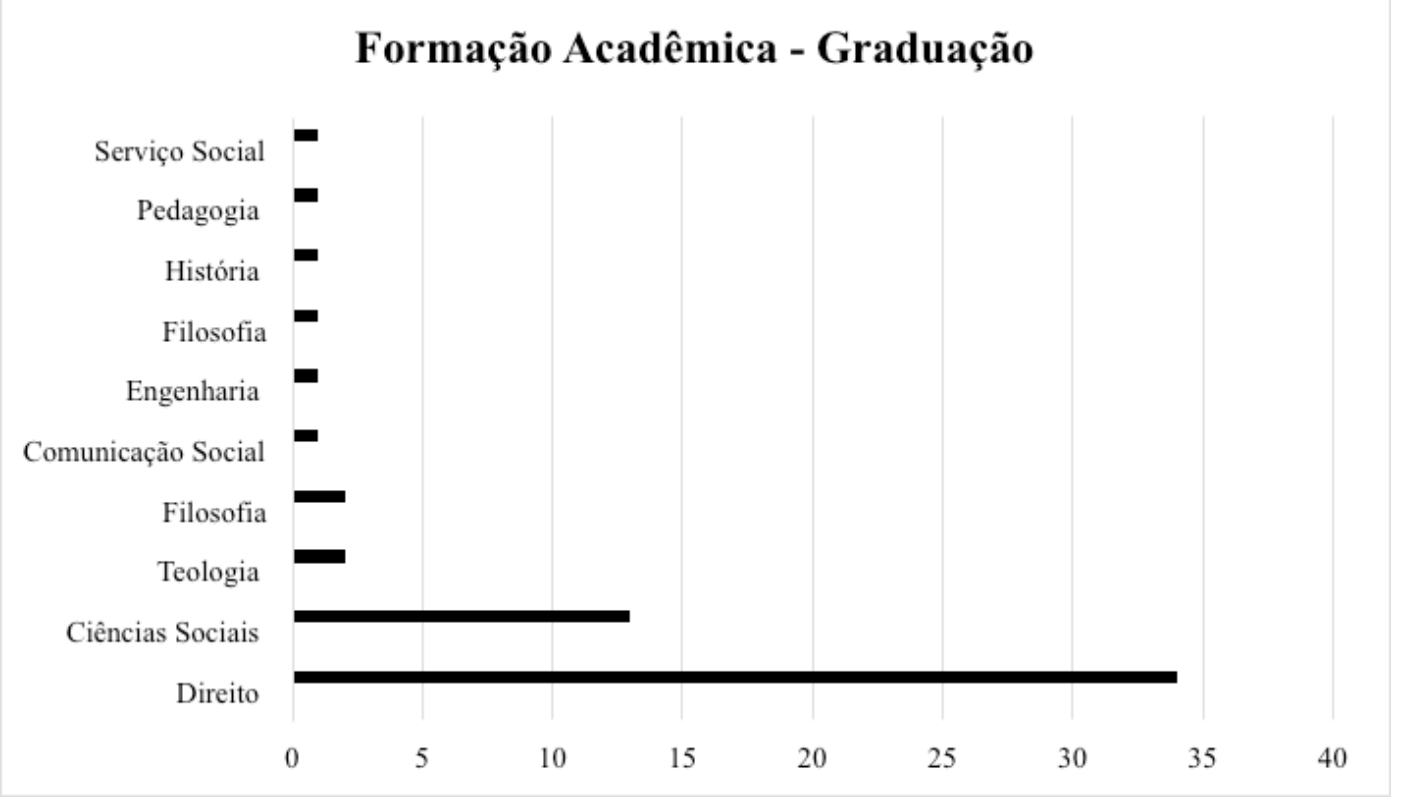


Em relação ao mestrado, a maior parte dos professores também elegeu o campo do direito para sua formação, de modo que 22 (vinte e dois) títulos analisados foram obtidos nesta área, ou seja, 44\%. Apenas 07 (sete) professores são mestres em sociologia (14\%),
O2 (dois) são mestres em desenvolvimento e meio ambiente, $\mathrm{O} 2$ (dois) em filosofia, $\mathrm{O} 2$ (dois) em psicologia, um possui título de mestrado interdisciplinar em sociologia e direito e os demais obtiveram seus títulos em áreas diversificadas, conforme gráfico abaixo:

\section{Gráfico 04: formação acadêmica do corpo docente em nível de mestrado}

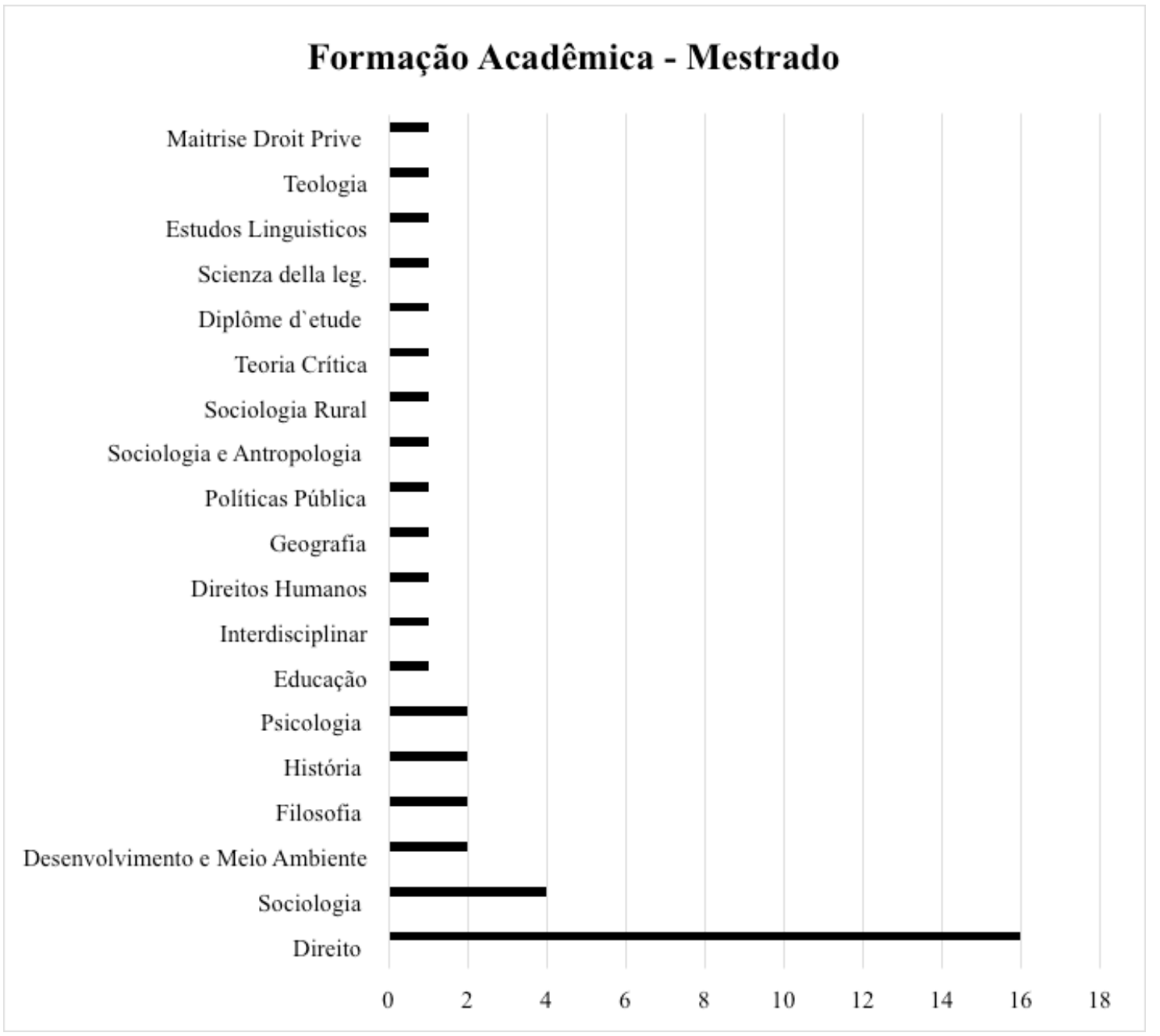

Fonte: elaboração própria.

Em relação ao doutorado, também se observa um maior número de títulos na área do direito, sendo que 15 (quinze) títulos analisados são em direito (44,11\%), 07 (sete) em sociologia (20,58\%), 01 (um) doutorado é interdisciplinar em sociologia e direito $(2,9 \%)$ e os demais se dividem em várias áreas, conforme gráfico abaixo: 


\section{Gráfico 05: formação acadêmica do corpo docente em nível de doutorado}

\section{Formação Acadêmica - Doutorado}

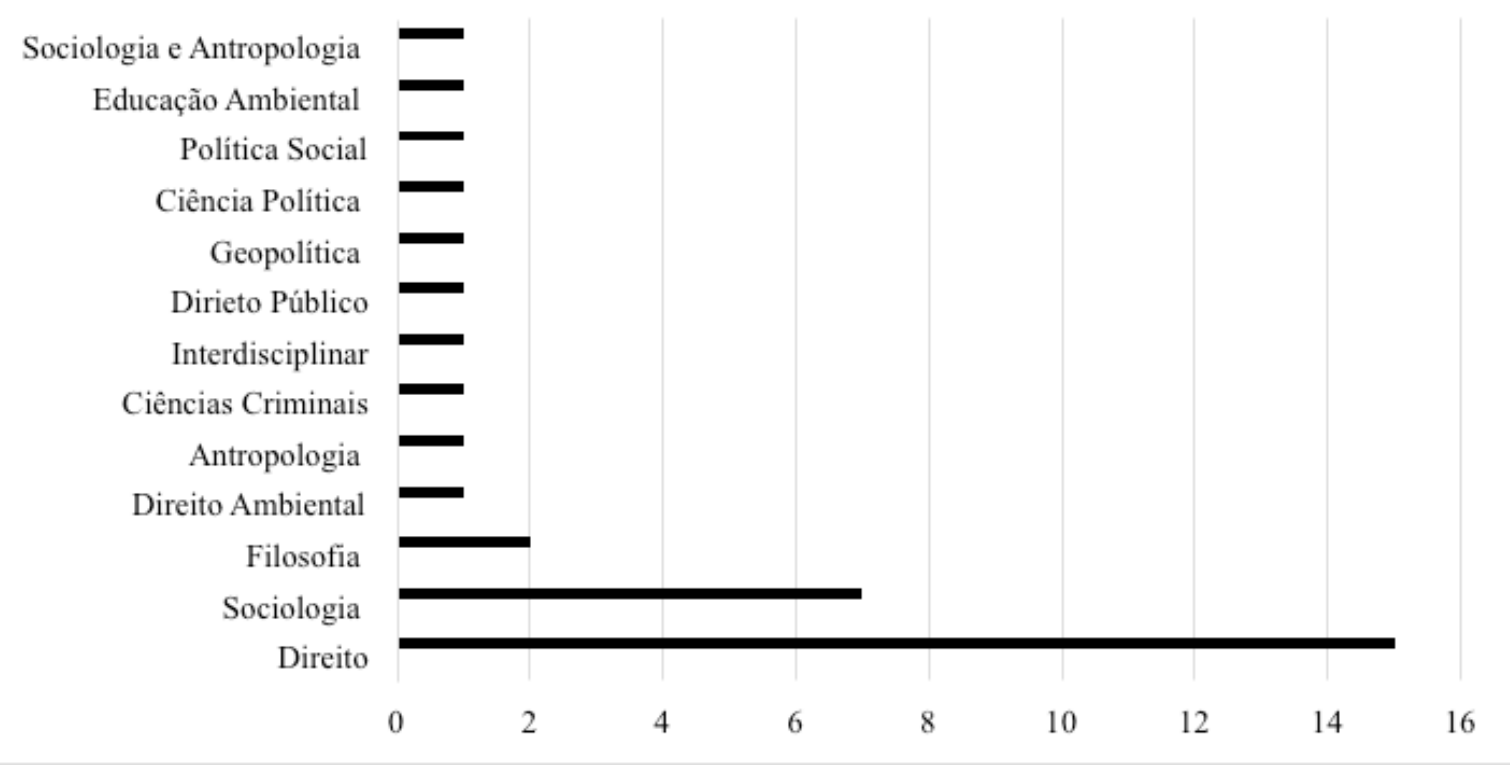

Fonte: elaboração própria.

No que se refere ao pós-doutorado, dos 18 (dezoito) cursos analisados, 03 (três) foram realizados na área de sociologia e 03 (três) na área de sociologia jurídica, 02 (dois) deles na área de direito e os demais em diversas áreas do saber, vejamos:

\section{Gráfico 06: formação acadêmica do corpo docente em nível de pós-doutorado}

\section{Formação Acadêmica - Pós-Doutorado}
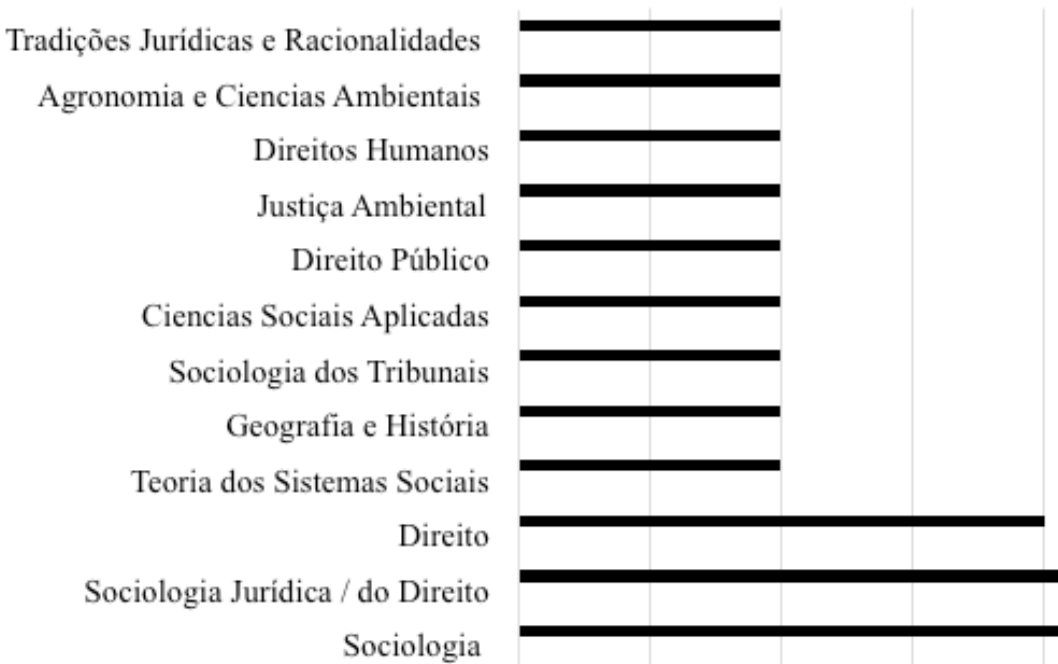

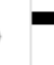

$$
0
$$


Dos dados analisados, verificou-se que dos 54 (cinquenta e quatro) professores, 18 (dezoito) deles já realizaram pós-doutorado (33,33\%), 20 (vinte) deles o de doutorado (37,03\%), 13 (treze) deles o de mestrado $(24,07 \%)$ e 03 (três) deles possui apenas a graduação (5,55\%), ou seja, trata-se de um grupo de docentes cuja formação acadêmica é elevada, sendo que mais da metade deles possui título de doutorado ou o pós-doutorado.

Assim, embora a grande maioria dos professores possua formação em direito, verifica-se que há também uma interação entre outros campos, principalmente de outras áreas das ciências sociais e das ciências sociais aplicadas, tal constatação mostra-se relevante para que os objetivos em direção à interdisciplinaridade sejam alcançados.

Outra constatação relevante é a de que embora a maioria das ementas e/ou bibliografias não compreendam conteúdos relacionados à pesquisa e à metodologia de pesquisa, a maior parte dos professores já esteve envolvida na realização de uma pesquisa de pós-graduação, deixando para trás a hipótese inicialmente ventilada, de que a ausência de previsão quanto às pesquisas ora desenvolvidas nas ementas e/ou bibliografias se deve ao desconhecimento do corpo docente em relação a elas. Porém, ao analisar a área do conhecimento em que as pesquisas de pós-graduação foram realizadas, verifica-se que a grande maioria foi desenvolvida em direito, por isso, não é possível verificar se, de alguma forma, estas se relacionam com a sociologia jurídica. Ou seja, embora o corpo docente tenha um alto grau de formação acadêmica, isso não conduz necessariamente ao conhecimento das pesquisas sociojurídicas realizadas atualmente.
Assim, constata-se uma distância entre os programas da disciplina e a trajetória acadêmica do corpo docente e, cotejando estes dados com os dados acima mencionados, em relação à tímida presença da temática da pesquisa nas ementas e/ou bibliografias das disciplinas, pode-se verificar uma nova hipótese, segundo a qual o perfil do professor de sociologia jurídica ou de sociologia do direito ainda encontra-se associado ao modelo epistemológico disciplinar e não temático, no qual a interdisciplinaridade encontra espaço.

\section{CARACTERÍSTICAS DO CAMPO CONSTATADAS A PARTIR DOS DADOS COLETADOS}

Como mencionado anteriormente, diferente do que previa a Portaria $n^{\circ} 1.884 / 96$, a ResoIução n 09/2004 do Conselho Nacional de Educação prevê que o curso de graduação em direito deve contemplar em seu projeto pedagógico e estrutura curricular conteúdos essenciais sobre sociologia, não havendo especificação quanto à sociologia jurídica, mostra-se como uma opção legislativa que não apresentou grandes mudanças práticas, já que, como visto nas tabelas 01 e 02, a maior parte das instituições pesquisadas (79,50\%) possui em sua estrutura curricular uma disciplina direcionada ao ensino do conteúdo específico de sociologia jurídica.

A opção por tornar o conteúdo como parte integrante da formação dos futuros juristas do país sempre esteve acompanhada de outro debate, mais antigo, em tornar a educação jurídica mais próxima da realidade, mais crítica e menos dogmática. Ao fazer um breve histórico da disciplina, Roberto Fragale chega à seguinte conclusão: 
Ora, o que se extrai, então, dessa brevíssima historia da disciplina? Creio que o traço comum a ser extraído encontra-se na vocação transformadora que sempre buscou-se emprestar à matéria e que se verifica, de forma simultânea, na ocorrência de uma recusa (a qual varia conforme o tempo) e um projeto (o qual apresenta traços comuns permanentes). Com efeito, em todos os reclamos pela sua inclusão nos currículos jurídicos, vê-se a existência de uma recusa, de um fundo comum de inconformismo com o estado precedente das coisas: primeiro com o Direito Natural; depois contra o divórcio do direito com a realidade; enfim, contra a alienação e o tecnicismo jurídico. Por outro lado, todos os pedidos de inclusão da matéria passam por um projeto comum: o empréstimo de uma cientificidade ao Direito, ainda que apresentem suas especificidades nos tópicos da democracia, do socialismo (Fragale Filho in Junqueira \& Oliveira, 2002, p. 121-122).

Nesse sentido, o autor encontra no binômio recusa-projeto uma característica essencial da disciplina, que parece estar presente até os dias atuais. A recusa ao ensino do direito dissociado da realidade pode ser vista, ainda que timidamente, pela própria redação da Resolução nº 09/2004, ao aduzir que os conteúdos que integram o eixo de formação fundamental dos projetos pedagógicos e estruturas curriculares, "tem por objetivo integrar o estudante no campo, estabelecendo as relações do Direito com outras áreas do saber", restando claro que o lugar ocupado pela sociologia é de estabelecer um diálogo entre os estudos do direito com os estudos sociológicos.
Verificou-se, tanto pela ótica normativa e bibliográfica, como pela ótica empírica, que a institucionalização da sociologia jurídica nos programas da faculdade de direito ocorreu de maneira peculiar. Isso porque, na medida em que a Resolução nº 09/2004 prevê, em seu artigo $5^{\circ}$, inciso I, que o curso de graduação em direito, em seu projeto pedagógico e estrutura curricular, deve contemplar conteúdo essencial de sociologia, não há uma exigência quanto à forma que este conteúdo irá aparecer, tampouco quais seriam esses conteúdos considerados essenciais. Abrem-se, portanto, diversas possibilidades para que cada instituição faça os seus projetos e currículos de modo a abranger os conteúdos de sociologia que Ihes parecem essenciais. Esta ausência de regulamentação e delimitação formal quanto ao conteúdo, a princípio, pode não trazer prejuízos ao ensino da sociologia jurídica nos cursos de direito.

Uma das constatações que pode ser realizada a partir dos dados obtidos na presente pesquisa é que a preocupação com a distinção entre o que seria objeto da sociologia do direito e da sociologia jurídica fica restrito aos estudos teóricos, de modo que na prática os conteúdos se misturam, não havendo uma preocupação do corpo docente em delimitar o alcance da matéria em sala de aula. Sendo assim, ainda que o presente estudo tenha tentado separar as ementas conforme o nome dado à disciplina, na tentativa de encontrar uma relação entre eles, o que se verificou foi a ausência de um padrão rígido a ser seguido pelas instituições, o que permite concluir que, na prática, o nome dado à disciplina não irá necessariamente representar o enfoque dado pelo curso, se o estudo de como o direito opera socialmente ou uma explicação sociológica do direito, contemplando, na grande maio- 
ria das vezes, as duas abordagens.

Por isso, a ausência de critérios quanto à articulação do nome com a ementa da disciplina não parece ser um problema, mas sim uma característica do campo. A esse respeito, Roberto Fragale menciona que:

(...) faz-se necessário uniformizar, apresentar uma delimitação precisa do conteúdo programático da matéria, a qual, como já evidenciado acima admite distintos enfoque? Creio que, não obstante todas as hesitações e contradições que a multiplicidade de abordagens pode provocar, a resposta deve ser negativa, pois estar-se-ia, assim, estrangulando o que parece constituir a maior riqueza da área, ou seja, sua diversidade (Fragale Filho in Junqueira \& Oliveira, 2002, p. 131).

Além disso, a despeito da ausência de critérios quanto à nomenclatura da disciplina e da diversidade de abordagens quanto à matéria, é possível verificar uma preocupação em definir os conteúdos próprios do campo da sociologia jurídica ou da sociologia do direito, aqui entendidos como sinônimos. Isso porque, apenas 8,95\% das ementas analisadas apresentam conteúdos relativos à filosofia e à teoria do direito, portanto ao longo dos anos houve uma delimitação e um refinamento quanto ao objeto da sociologia jurídica, diferenciando-o do objeto de outras disciplinas e fixando os parâmetros de seus próprios estudos.

Todavia, este dado se contrasta com o fato de que 19,23\% das bibliografias analisadas no presente estudo utilizam livros e textos de filosofia geral ou de filosofia do direito. Esta situação, por si só, não demonstra uma fragilidade do campo, na verdade, considerando que a Resolução n 09/2004 do CNE privilegia a interdisciplinaridade, estes tex- tos, se usados como forma de diálogo com os demais textos de sociologia e de sociologia jurídica indicados nas bibliografias podem ser importantes ferramentas para a concretização da intenção do legislador. José Eduardo Faria e Celso Fernandes Campilongo (1991, p. 31) embora ressaltem a diferença de método e de pressupostos filosóficos entre a sociologia do direito, a filosofia do direito e a teoria geral do direito, ainda que a estas últimas tenha sido atribuído enfoque sociojurídico, também reconhecem a existência de um denominador comum, como sendo um "desejo sempre confessado de também avaliar as normas a partir de um ângulo externo, sem submeter-se a elas nem às regras internas de produção do discurso jurídico para compreendê-las na sua história e nos seus efeitos".

Outro ponto importante ressaltado por Eliane Junqueira (2002, p. 67) é o fato de que "a bibliografia apresentada pelos professores não corresponde à efetivamente utilizada. Trata-se mais de uma bibliografia sugerida, do que da bibliografia trabalhada em sala de aula".

Em relação à pesquisa, constatou-se uma presença tímida deste conteúdo nas ementas analisadas, tanto com relação à metodologia, como dos temas atuais de pesquisa realizadas na área ainda é muito tímida (11,94\%), de modo que o projeto da sociologia jurídica apontado por Roberto Fragale (in Junqueira \& Oliveira, 2002) de emprestar ao direito uma certa cientificidade, pelo menos a nível de graduação, ainda não está completo, pelo contrário, constatou-se uma falta de entrosamento entre o que está acontecendo no campo acadêmico da sociologia jurídica com o que está sendo apresentado aos alunos da graduação. 
Nesse sentido, embora a sociologia jurídica seja um conteúdo que já encontra seu espaço de institucionalização nos cursos de direito, verifica-se que esta encontra limitações às suas possibilidades de inserção no campo jurídico, criadas pelo próprio corpo docente, que não se interessa em levar aos alunos de graduação aquilo que está sendo discutido e pesquisado. Esta constatação já havia sido levantada por José Eduardo Faria e Celso Fernandes Campilongo, ao afirmarem que:

O indigitado "estrito caráter científico" exemplifica bem o tipo de obstáculo epistemológico enfrentado pela Sociologia Jurídica brasileira. Tal discurso define sua preocupação como "toda limitada à esfera do direito". As abordagens que escapam à sua lógica são rotuladas de "não jurídicas". Levanta-se, desse modo, o obstáculo epistemológico: resistências intelectuais que bloqueiam, travam e desnaturam a produção de conhecimentos científicos. Ao definir "as tarefas dos juristas e só dos juristas", essa postura cria um fabulado "campo científico" que, sem sutilezas, suprime os espaços que a Sociologia Jurídica e, por extensão, a própria realidade social ocupam na reflexão sobre o direito (Faria \& Campilongo, 1991, p. 33-34).

Nesse mesmo contexto, verificou-se que em $86,53 \%$ dos programas de disciplina analisados os conteúdos de sociologia jurídica são apresentados aos alunos por meio de $\mathrm{Ma}$ nuais, demonstrando a ausência de inovação e criatividade dos professores ao apresentarem os conteúdos. Os gráficos 08, 09, 10 e 11 demonstram que o corpo docente da disciplina é formado por profissionais cuja formação acadêmica é elevada, sendo que mais da metade deles possuem o título de doutorado ou já fizeram um pós-doutorado.
Todavia, o que chama a atenção em relação a este aspecto é justamente o fato de que a trajetória acadêmica deles foi construída, em sua maioria, no campo do direito, já que a maior parte das graduações $(62,96 \%)$ foi feita na faculdade de direito e o mesmo acontece com as pós-graduações, que tanto no mestrado (44\%), como no doutorado $(44,11 \%)$ a maior parte dos títulos também foi obtida em programas vinculados ao curso de direito. Estes dados nos permitem chegar a uma conclusão quanto ao corpo docente da disciplina de sociologia jurídica, no sentido de que tendo uma formação majoritariamente jurídica, os professores não estão familiarizados com os temas próprios deste campo, razão pela qual esta bibliografia não aparece com tanta frequência. Por outro lado, verifica-se um grande número de manuais de sociologia jurídica ou de sociologia do direito indicados como bibliografia dos cursos, o que pode ser uma consequência da própria formação jurídica do corpo docente, tendo em vista a ampla utilização de manuais nos cursos jurídicos como um todo.

Dos dados acima, verifica-se que a sociologia jurídica nos cursos jurídicos está em grande parte preocupada em recusar o estudo do direito unicamente pela dogmática jurídica, abrindo-se aos olhares externos das ciências sociais. Todavia, no que se refere aos métodos de pesquisa e os estudos de pesquisas já realizadas, este ainda se mostra um caminho não muito explorado pelo corpo docente.

\section{CONCLUSÃO}

A presente análise foi realizada a fim de verificar em que direção está sendo realizada a institucionalização da sociologia jurídica 
como campo científico nas faculdades de direito no Brasil, o que permitiu verificar que embora promissor, ainda estamos diante de um campo em formação.

Assim, partindo da ideia de que a disciplina encontra no binômio recusa-projeto uma de suas características marcantes, a análise dos currículos das faculdades de direito levou em consideração aspectos relevantes sobre a constituição da própria disciplina, sobre os conteúdos abordados, sobre a bibliografia escolhida e sobre o corpo docente.

Os dados revelam, além da existência de um espaço de institucionalização da sociologia jurídica como disciplina das faculdades de direito, também a existência de uma preocupação, por parte do corpo docente, em delimitar e refinar o objeto de estudo da sociologia jurídica, na tentativa de apresentar aos alunos do curso de direito os conteúdos próprios da disciplina, não confundindo com os conteúdos de filosofia, teoria do direito e filosofia.

Quanto ao projeto metodológico da disciplina, a presença tímida em relação à pesquisa nas ementas revelou que esta preocupação aparece, ainda, em segundo plano, demonstrando, também, uma falta de entrosamento com as pesquisas desenvolvidas no campo da sociologia jurídica em nível de pós-graduação e os conteúdos debatidos com os alunos de graduação.

Considerando que a formação do corpo docente da disciplina foi realizada, em grande parte, no campo do direito, este dado pode revelar uma ausência de conhecimento quanto à produção científica do campo da sociologia do direito, como também um fechamento destes profissionais, altamente especializados no campo jurídico, para o que vem sendo produzido em outros campos.
Neste contexto, da análise realizada observa-se que embora a sociologia jurídica tenha encontrado um espaço de institucionalização dentro da faculdade de direito, o que era uma reivindicação antiga da parcela mais crítica dos estudiosos deste campo, outros fatores mostram que houve uma aglutinação do conteúdo pelo campo do direito, o que pode dificultar a consolidação da sociologia jurídica e a relevância desta nos cursos jurídicos e, no limite, na formação acadêmica, refletindo na prática profissional.

\section{REFERÊNCIAS}

Brasil. LEI No. 9.394, de 20 de dezembro de 1996. Estabelece as Diretrizes e Bases da Educação Nacional. Diário Oficial da República Federativa do Brasil, Brasília, DF, n. 248, 23/12/1996. P. 27.833-841.

Brasil. Ministério da Educação. RESOLUÇÃO N. 9, de 29 de setembro de 2004. Brasília, 2004. Disponível em: <http://portal.mec.gov.br/cne/arquivos/pdf/rces09_04. pdf>. Acesso em: 15 out. 2017.

Brasil. Portaria n 1.886, de 30 de dezembro de 1994. Fixa as diretrizes curriculares e o conteúdo mínimo do curso jurídico. Brasília, 1994. Disponível em: <http:// www.migalhas.com.br/arquivo_artigo/art20100108-03. pdf>. Acesso em: 15 out. 2017.

Campilongo, C. F. (2000). Direito e democracia. 2. ed. São Paulo: Max Limonad.

Engelmann, F. (2006). Elementos para uma sociologia da diversificação do campo jurídico brasileiro pós-redemocratização. Florianópolis: Revista de Ciências Humanas, n³9, p. 99-115

Engelmann, F. (2015). Sentidos Políticos da Reforma do Judiciário no Brasil. Rio de Janeiro: Revista Direito e Práxis, vol. 07, n 12, p.395-412.

Faria, J. E. (Org.) (2009). A crise do direito numa sociedade em mudança. Brasília: UNB.

Faria, J. E. (1984). Sociologia jurídica: crise do Direito e práxis política. Rio de Janeiro: Forense.

Faria, J. E. (1987). A reforma do ensino jurídico. Porto Alegre: Sérgio Antonio Fabris Editor.

Faria, J. E. (2010). Sociologia jurídica: direito e conjuntura. 2. ed. São Paulo: Saraiva.

Faria, J. E. \& Campilongo, C. F. (1991). A sociologia jurí- 
dica no Brasil. Porto Alegre: Fabris.

Fragale Filho, R (2002). Variações sobre o mesmo tema. In: JUNQUEIRA, Eliane Botelho; OLIVEIRA, Luciano. (Org.). Ou isto ou aquilo: a sociologia jurídica nas faculdades de Direito. Rio de Janeiro: Letra Capital, p. 115-133.

Junqueira, E. B. (1993). A sociologia do direito no Brasil: introdução ao debate atual. Rio de Janeiro: Lumen Juris.

Junqueira, E. B \& Oliveira, L. (Org.) (2002). Ou isto ou aquilo: a sociologia jurídica nas faculdades de Direito. Rio de Janeiro: Letra Capital.

Rodrigues, H. W (2005). Pensando o ensino do direito no século XXI: diretrizes curriculares, projeto pedagógico e outras questões pertinentes. Florianópolis: Fundação Boiteux.

; Junqueira, E. B. (2002). Ensino do direito no Brasil: diretrizes curriculares e avaliação das condições de ensino. Florianópolis: Fundação Boiteux.

Santos, B. S. (2007) Para uma revolução democrática da justiça. São Paulo: Editora Cortez.

Wander, B. A (2000). O ensino jurídico no Brasil. 2. ed. Rio de Janeiro: Lumen Juris.

Data de submissão: 25/02/2019

Data de aceite: 13/03/2020 